\title{
Moralización y catolicismo al arribo de la televisión. Ciudad de México y Bogotá, 1950-1965*
}

\author{
Laura Camila Ramírez Bonilla**
}

El objetivo principal de esta investigación fue rastrear las trayectorias que siguieron el catolicismo y la moralización ante el surgimiento de un nuevo medio de comunicación masivo y audiovisual: la televisión. Se trata de un relato de sincronías y discrepancias, entre la religión y la técnica, en dos ciudades con regímenes religiosos y televisivos diferentes. Primero, un estado constitucionalmente laico, como el de México, en contraste con uno confesional, como el colombiano. Y segundo, la experiencia de un sistema de televisión privado, como el mexicano, en contraste con un sistema estatal posteriormente mixto-, como el de Colombia.

Bajo estos parámetros, la investigación sostiene que en los encuentros entre moralización, catolicismo y televisión es posible estudiar las sociedades urbanas de los años cincuenta y principios de los sesenta en América Latina, sus transformaciones socioculturales, sus preocupaciones por el orden social y sus expectativas por conservar y aplicar los códigos de la moral católica al anhelo modernizador de la época.

* La tesis que se presenta fue asesorada por el doctor Marco Palacios Rozo y defendida el 8 de mayo de 2017 en El Colegio de México para obtener el grado de Doctora en Historia. Fue ganadora de la "Mención Honorífica a la Mejor Tesis de Doctorado, 2018" que otorga la Comisión de Historia del Instituto Panamericano de Geografía e Historia. Se puede consultar en el siguiente enlace:

https://colmex.userservices.exlibrisgroup.com/view/delivery/52COLMEX_INST/12845629 10002716

** Doctora y maestra en Historia por El Colegio de México, maestra en Estudios Políticos por el Instituto de Estudios Políticos y Relaciones Internacionales de la Universidad Nacional de Colombia y politóloga de la misma institución. Sus áreas de investigación en historia contemporánea de México y Colombia se centran en: 1. Relaciones entre Iglesia, política y sociedad; 2. Procesos de construcción de paz; 3. Historia de la televisión. Actualmente es académica de tiempo completo en el Departamento de Historia de la Universidad Iberoamericana, Ciudad de México, México. 
Tanto en México como en Colombia, la televisión surge en un contexto político y eclesiástico conservador. El escenario se caracterizó por un rearme moralizador que revitalizó la actividad de asociaciones católicas de laicos y jerarcas preocupados por los avances de la modernización y la técnica y sus consecuencias en la conducta de los individuos. Moralización y televisión coinciden en lugares cada vez más urbanizados y profesionalizados, en franco crecimiento demográfico y expansión de clases medias, en un genuino afán industrializador y en consolidación de una cultura de masas.

En ese marco, esta tesis estudió la televisión como una entidad de significados con itinerarios históricos propios, interpretables sólo en conexión con los marcos culturales en los que se desarrolla. Así, su incursión en el relajamiento y reforzamiento de esquemas morales se explica, entre otros factores, por: el poder de la imagen - en movimiento, sincronizada con el sonido-, el sentido masivo del medio, la inmediatez que supone transmitir "en vivo", su capacidad de representación y mímesis de la realidad, la novedad de la experiencia — sensorial, cognitiva, cotidiana - pero sobre todo, la dimensión doméstica del medio, "su presencia en casa", santuario de la familia y primer difusor de pautas de comportamiento. En ese marco, se reiteró, por un lado, que la historia de un medio de comunicación no es neutral a los contextos y los sistemas de valores donde éste surge y opera. Y por otro, que es posible "historizar" órdenes morales, entendidos como "artificios humanos", inherentes al impulso de los hombres a querer organizar la conducta en sociedad.

En particular, la investigación se detuvo en la lectura de recelo que los sectores más conservadores de la Iglesia de los cincuenta — clérigos y laicos- formularon frente a los contenidos y la forma de operar de la televisión, los intentos por encauzarlo hacia los códigos católicos de comportamiento social y las respuestas que produjeron otros segmentos de la institución eclesiástica desde la oportunidad de tener un nuevo canal de comunicación al servicio de la fe. Las acciones fueron desde los señalamientos en prensa hasta las denuncias ante autoridades civiles, llamados de atención a las televisoras, productores y artistas, intentos de clasificación moral de contenidos, formación de teleclubes, códigos de conductas, propagandas, reflexiones y difusión de orientaciones. Ciertamente, el ejercicio remite a un catolicismo que continúa detentando, en los dos casos, una autoridad aprobada en torno a la moral pública, sin una oposición tajante de la clase política y el Estado - laico o confesional. La familia, la niñez, la decencia, las buenas costumbres y el influjo de la comunicación masiva definieron la agenda de los conservadores moralistas frente al nuevo medio.

En este punto es clave resaltar la aparición de un nuevo actor en el panorama de las comunicaciones: el televidente, un agente que, pese a ser "neófito", está lejos de entenderse como un mero receptáculo de contenidos. A 
mediados del siglo XX, el acto de "ver televisión" fue una compleja experiencia de mediaciones materiales y simbólicas, que implicó sociabilidades, negociaciones, adaptaciones y críticas. Hablamos de una recepción interactiva, contextualizada, que resignificó lo observado. Se detectó un público que, independientemente del sentido conservador y moralizante de su actuar, complejizó todo el acto comunicativo, interactuando directamente con lo proyectado en pantalla.

Desde la perspectiva eclesiástica, estos medios fueron concebidos como instrumentos al servicio de la fe, productos del ingenio con el que Dios había dotado a los humanos. Sin embargo, en paralelo a la desconfianza moral, surgió en la misma Iglesia un sector aperturista que se empezó a interesar por la televisión como fenómeno sociocultural y buscó formar profesionales en el área. Se trata de una facción que no dudó en acatar los llamados pontificios (Pio XII, Juan XXIII y Pablo VI) hacia un conocimiento y uso más estratégico de los medios masivos en la difusión del pensamiento católico.

Ahora bien, ante lo operativo y metodológico, no es posible afirmar que esta investigación sea una historia de la televisión, tampoco se trata de una historia de la moralización en México y Colombia, ni constituye una historia de la Iglesia. El relato remite a los cruces de estos tres procesos históricos, sus contradicciones y articulaciones. La investigación de dichos encuentros en dos ciudades distintas buscó responder a preguntas comunes que provocaran una interlocución constante, más que una comparación categórica. El ejercicio exigió comprender las trayectorias de cada ciudad en conexión con lo nacional, lo regional y lo global. El trabajo de archivo estatal y eclesiástico, la historia oral, la hemerografía y el análisis de la imagen, principales metodologías de la investigación, comprobaron que es factible leer el orden moral predominante de un período y espacio determinados a la luz del surgimiento de nuevas tecnologías de las comunicaciones, sus contenidos, su inserción en el ambiente sociocultural y político y la recepción de distintos sectores sociales. En este proceso, acceder a material audiovisual y archivo de las televisoras y programadoras privadas fue la mayor dificultad presentada en las pesquisas de archivo.

Es preciso indicar que, para complementar la perspectiva pontificia sobre la moralización y la televisión, en 2014 se realizó una estancia de investigación en Roma con el apoyo de Conacyt y El Colegio de México. En el Archivo Secreto Vaticano se revisaron fondos sobre Colombia y México en las décadas de mayor actividad de Acción Católica, archivos del Concilio Vaticano II -Sección Secretaría General-, en los folios correspondientes a medios de comunicación, así mismo, se revisaron carpetas variadas sobre la creación de una institucionalidad católica en torno al cine, la radio y la televisión a partir de 1928. La estancia incluyó la recolección de bibliografía, información y archivo - escrito y audiovisual, hemerográfica y fotográfi- 
ca - en la Biblioteca Vaticana, la Filmoteca Vaticana, el Centro Televisivo Vaticano, el Observatorio Romano, la Biblioteca Central de Roma - Hemeroteca- y la Asociación Católica Mundial para la Comunicación. Esta diversidad de documentos primarios, sumados a los señalados arriba, exige al historiador un ejercicio de sistematicidad y creatividad riguroso y amplio, el cual abre nuevos caminos para el estudio histórico tanto de los medios de comunicación audiovisuales como los sistemas de símbolos y valores que una religión asigna a una sociedad.

Son reducidos los estudios académicos sobre moralización y televisión, más aún desde una perspectiva histórica. La situación contrasta con el tratamiento que se le ha dado al cine, la prensa, el teatro o la radio, en los siglos XIX y XX. Las investigaciones sobre moralidad y televisión están enfocadas en análisis semióticos, filosóficos y sociológicos sobre géneros televisivos. El libro de Wenceslao Castañares, La televisión moralista (2005), aborda la relación entre moral y televisión mediante el análisis de reality shows ${ }^{1}$ en España. Entre otras tesis, Castañares plantea que la televisión no fue viable sino hasta el momento en que la familia estuvo preparada para consumirla. ${ }^{2}$ De ahí parten las múltiples representaciones, usos y concepciones que se construyeron a su alrededor y de la moral. Por su carácter simbólico, no es extraño que desde sus inicios — hasta nuestros días - el medio haya sido calificado como un "mal potencial". ${ }^{3}$ Tim Dant, de la Universidad de Lancaster, realiza un enfoque desde la sociología. El autor afirma que la moral está involucrada con la interacción que los espectadores entablan con los contenidos televisivos. ${ }^{4}$ Su libro Television and the Moral Imaginary (2012) argumenta que el medio es uno de los principales instrumentos por los cuales se comparten ideas morales. ${ }^{5}$ Este trabajo se une a una serie de investigaciones académicas que en los últimos años han retomado la relación entre televisión y moralidad desde los estudios culturales. Su perspectiva no

1 El reality show es un género televisivo que presenta a concursantes compitiendo por un objetivo específico, su característica más común es documentar a sus personajes en comportamientos reales o cotidianos, en medio de situaciones excepcionales.

2 Castañares, La televisión moralista, pp. 26, 27 y 31.

3 Éste es el caso del libro La televisión es mala maestra (1995), de Karl Popper y John Condry, quienes reúnen a varios intelectuales y académicos, entre ellos a Karol Wojtyla, para reflexionar sobre la función educativa de la televisión. Su perspectiva parte de una disyuntiva moral: "es potencialmente evidente que la televisión, así como es una tremenda fuerza para el mal, podría ser una tremenda fuerza para el bien". En una perspectiva no muy distante se halla la tesis de Giovanni Sartori sobre el homo videns: el surgimiento de una cultura para la cual la palabra está demostrada por la imagen, dejando atrás al homo sapiens de la cultura escrita. Popper, "Una patente para producir televisión”, p. 38. Wojtyla, "La potencia de los medios de información”, pp. 51-52. Sartori, Homo videns. Primera edición en 1997.

4 Dant, "Morality and the phenomenology of television", pp. 7-8 y 16.

5 Dant, Television and the Moral Imaginary: Society Through the Small Screen, pp. 2, 24-39. 
es histórica, sin embargo, hacen un esfuerzo por vincular las dos temáticas en coyunturas y casos específicos. ${ }^{6}$ Las investigaciones de Roger Silverstone, La moral de los medios de comunicación (2007) y Televisión y vida cotidiana (1994), fueron referencias importantes para comprender la "domesticidad" del medio, en especial, su relación con la "formación del espacio social, cívico y moral". 7

Nos encontramos ante un campo desatendido por el análisis histórico que confronte contextos, antecedentes, fuentes documentales y conexiones con otros fenómenos sociales. Las investigaciones académicas que se cuestionan por el tema hacen uso de la historia como apoyo argumentativo o antecedente, ${ }^{8}$ no como un objetivo prioritario. ${ }^{9}$

La estructura de la tesis se planteó en siete capítulos. El primero se detiene en los años previos a la instalación de la televisión en Colombia y México. El segundo remite al surgimiento oficial de dos actores: la televisión, como nuevo canal comunicativo, y el televidente, como receptor diferenciado y activo. El tercer capítulo reconstruye el discurso y la institucionalidad pontificia frente a los medios audiovisuales de comunicación. El cuarto se dedica a los espectadores y los moralizadores. La filiación del primero como "televidente-creyente" y la acción de los segundos como militantes de una causa. El capítulo quinto se concentra en la inserción del nuevo medio en la vida doméstica y el dilema moral que representó. ¿La televisión podía pervertir a la familia o propiciaba su unión y entretenimiento sin exponerse a los peligros de la calle? El capítulo sexto observa la relación de los niños con la televisión, entendiendo a la infancia como el principal foco de aten-

6 Al respecto destacaría dos textos: "Children, Television and Morality, 1950s to 2000s: A Sociological Perspective" (2008), de David Oswell, de la Universidad de Londres, y el libro "Morality and social order in television crime drama" (1996), de John Sumser, publicado por McFarland en Estados Unidos. Igualmente, "Phatic morality: Television and proper distance" (2013), de Paul Frost, de la Universidad Hebrea de Jerusalem, quien aborda el tema desde el lenguaje y el concepto "proper distance". Igualmente encontramos "Morality, Mystery, Meaning, and Memory: Decoding Audience Perceptions of Television and New Religiosity" (2004), de Wendy K. Martin del Departamento de Estudios Clásicos y Religiones de la Universidad de Ottawa. Finalmente, se destaca un singular estudio sobre salud pública y moralidad: "IIt's disgusting how much salt you eat!' Television discourses of obesity, health and morality", fue publicado por Sanna Inthorn y Tommy Boyce, el texto se encuentra en: http://ics.sagepub.com/content/13/1/83, consultado el 10 de febrero de 2014 .

Silverstone, La moral de los medios de comunicación, pp. 18-19.

Es éste el caso del libro de Gustavo Bueno, Televisión: apariencia y verdad (2000).

Al respecto hay numerosas referencias. La moralidad puede ser uno de los aspectos a analizar en este tipo de estudios. Es el caso del libro de David Hesmondhalgh y Jason Toynbee: The Media and Social Theory (2008), que contiene un capítulo, escrito por Helen Wood y Bev Skeggs, en el que abordan el tema a propósito de la clase obrera. El texto se tituló: "Spectacular Morality: Reality Television, Individualisation and the Remaking of the Working Class". 
ción de los moralizadores. Y el séptimo capítulo aborda el agotamiento del discurso moral y el comienzo de una postura más progresista, con clérigos expertos en el mundo televisivo, la llegada del Concilio Vaticano II y un tono más pragmático que doctrinal en el apostolado de los medios masivos de difusión.

A mediados del siglo XX, moralización, catolicismo y televisión constituyeron una dialéctica fluida, aunque poco conocida. Se trató de una mutua referenciación que, en el detalle de los hechos, nos habilita para aproximarnos a los cambios y las reticencias de las sociedades urbanas latinoamericanas de la época. Es una suerte de lupa que admite ir de lo "micro" a lo "macro" y regresar a la vez de lo "macro" a lo "micro" en el análisis histórico, reconocer los influjos de lo global en lo local e identificar las concurrencias y particularidades en dos experiencias puntuales. Ciertamente, quedan tópicos, fuentes, herramientas y enfoques por integrar al estudio. Sin embargo, se abre una agenda de investigación versátil y original, con amplias opciones de crecimientos. Me refiero, además, a una agenda con plena vigencia, presente en los altos niveles de desconfianza que los medios de comunicación, en especial la televisión, hoy registran entre las audiencias; los impactos diferenciales de las pantallas en las decisiones de los individuos; el juego que continúan teniendo en la configuración de órdenes morales y la competencia reciente con medios digitales y redes sociales.

\section{BiBLIOGRAFÍA}

Bourdieu, Pierre, Sobre la televisión, Barcelona, Anagrama, 2001.

Bueno, Gustavo, Televisión: apariencia y realidad, Barcelona, Gedisa, 2001.

Castañares, Wenceslao, La televisión moralista, Madrid, Fragua, 2005.

Dant, Tim, "Morality and the phenomenology of television". Disponible: http://www.lusi.lancs.ac.uk/OnlineCoursesHandbook/ModuleCatalogue/ Module.aspx?Course $=010790 \&$ Year $=000109$

—, Television and the Moral Imaginary: Society Through the Small Screen, Lancaster, Palgrave Macmillan, 2012.

Poper, Karl, La televisión es mala maestra, Ciudad de México, Fondo de Cultura Económica, 2006.

Sartori, Giovanni, Homo Videns. La sociedad teledirigida, Ciudad de México, Taurus, 2015.

Silverstone, Roger. La moral de los medios de comunicación, Buenos Aires, Amorrortu editores, 2007. 